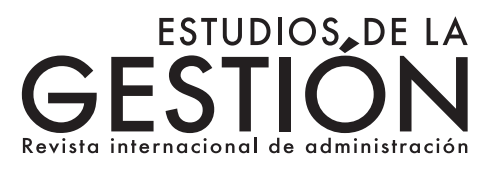

\title{
Educación para el emprendimiento en la universidad
}

\author{
César Vásquez \\ Universidad Politécnica Salesiana (Ecuador) \\ cvasquez@ups.edu.ec
}

Fecha de presentación: 9 de julio de 2015 • Fecha de aceptación: 22 de junio de 2016 Artículo de investigación 


\section{Resumen}

El panorama de la proyección innovadora de la universidad, en función del desarrollo del emprendimiento, demanda una comprensión de todas las perspectivas teórico-metodológicas que versan sobre su conceptualización y praxis. Este artículo analiza la problemática del emprendimiento y sus implicaciones educativas, con el propósito de sentar las bases teórico-conceptuales para la orientación formativa de su contenido y su implementación en las instituciones de educación superior.

Palabras clave: creatividad, educación, emprendimiento, innovación, sistémico.

JEL: I23 Centros de enseñanza superior y de investigación; M53 Formación.

\section{Abstract}

The panorama of the innovative projection of the university, in function of the development of entrepreneurship, demands an understanding of all the theoretical - methodological perspectives that turn on their conceptualization and praxis. This article analyzes the problems of entrepreneurship and its educational implications, with the purpose of laying the theoretical-conceptual foundations for the formative orientation of its content and its implementation in higher education institutions.

Keywords: creativity, education, entrepreneurship, innovation, systemic.

JEL: I23 Higher education and research centers; M53 Training.

\section{Resumo}

O panorama da projeção inovadora da universidade, em função da desenvolvimento do empreendedorismo, exige uma compreensão de todas as teorías perspectivas metodologicas que transformam sua conceituação e praxis. Este artigo analisa os problemas do empreendedorismo e suas implicações educacionais com o objetivo de colocar as bases teórico-conceituais para a orientação formativa do seu conteúdo e sua implementação no ensino superior instituições.

Palavras-chave: Criatividade, educação, empreendimento, inovação, sistêmico.

JEL: I23 Centros de ensino superior e de pesquisa; M53 Formação. 


\section{Introducción}

1 emprendimiento puede considerarse un ámbito cognoscitivo relativamente nuevo en el espectro global de la investigación (Herrera y Montoya 2013). Esta realidad se advierte a partir de la emergencia y consolidación del tópico en la segunda mitad del siglo pasado, fundamentalmente a partir de la década del 90, con la aparición de un número importante de trabajos dedicados a la temática.

Los autores sistematizaron progresivamente la idea de concebirlo como un área de intercepción de saberes lógicos, actitudinales y procedimentales, garantes de la gestación, desarrollo e implementación de proyectos orientados a una amplia gama de sectores concomitantes en las esferas sociales, culturales, políticas, económicas, productivas y de los servicios (Stevenson y Jarillo 1990; Sela y Bacarini 2009; Mello 2011; Pedraza, Ortiz y Pérez 2015).

Ahora bien, es en este contexto que se ha planteado desde casi todos los estamentos del emprendimiento, en las distintas esferas, como la única posibilidad para la mejora de condiciones de la sociedad en su conjunto y, que la universidad, a través de sus proyectos y programas, debería ser quien plantee y posibilite que todos y cada uno de sus educandos, de manera transversal, en su proceso formativo deban adquirir las necesarias y suficientes destrezas y competencias que permitan convertirse en profesionales visionarios que viabilicen la creación de nuevas oportunidades y empresas. La universidad en general, desde hace algún tiempo, ha planteado en sus principios filosóficos la formación del emprendedor visionario como una de sus principales premisas, pero en la estructura de sus diseños curriculares no ha sido debidamente incluidos, y no se ha aterrizado en la aplicación práctica de esos principios.

Desde esta óptica es menester reflexionar sobre una cuestión primaria, referida a la asunción del emprendimiento, en virtud de los postulados científicos que sustentan la racionalidad de este tema, y las posibles proyecciones 
del mismo en el contexto socioeducativo de una universidad innovadora. Precisamente, esta es una cuestión que es necesaria tratar a los efectos de visualizar su contenido y alcance en la dinámica de las funciones sustantivas de las universidades: docencia, investigación y vinculación con la sociedad.

En virtud de ello, el trabajo que se presenta asume como principal objetivo el abordaje crítico de los referentes teórico-metodológicos que sustentan la relación universidad-emprendimiento, a efectos de generar una perspectiva de análisis educativo que promueva la proyección formativa del emprendimiento en el contexto de una universidad innovadora.

\section{Metodología}

Tomando en cuenta que el análisis que se realizó se sustenta en un razonamiento epistemológico, la investigación bibliográfica es la pertinente para el tema que se analiza desde distintas perspectivas; se revisaron conceptos y postulados contemporáneos, así como criterios que mantienen su vigencia y validez, para acercarnos a la realidad que vive y en el que se desarrolla el emprendimiento en las universidades del Ecuador.

El desarrollo de este artículo se estructuró tratando, en primera instancia, de brindar una visión y conceptualización del tema desde varios puntos de vista, buscando incluir las formas o maneras en que esta ha clasificado para después revisar cómo se considera al emprendimiento y, a partir de estas premisas, visualizar cómo se orienta la educación universitaria en sentido del desarrollo del emprendimiento, así como analizar el papel de la universidad a través de procesos formativos, educativos y de capacitación en pos de lograr la innovación y la investigación en función del desarrollo y la interacción social y en la búsqueda de cumplir con el precepto de hacer docencia-empresa; finalmente, se realizan recomendaciones de requerimientos para convertir a la universidad en formadora de emprendedores visionarios e innovadores. 


\section{El desarrollo del emprendimiento y sus implicaciones formativas}

Convencionalmente se relaciona el concepto de emprendimiento con la actividad vinculada a los procesos de creación de empresas, prevaleciendo en este sentido una visión economicista en su concepción. Entiéndase con esta aclaración no una crítica a la perspectiva económica del contexto empresarial, sino al sobredimensionamiento de esta perspectiva en el sentido de su consideración como único espacio de realización empresarial.

El origen semántico del término emprendimiento encuentra su génesis en la palabra francesa entreprende, cuya traducción supone hacer algo. Este concepto llegó a emplearse en el medioevo para distinguir a los individuos que eran capaces de alcanzar lo que se proponían mediante un conjunto de acciones meditadas y oportunas que implicaban no solo "hacer algo", sino hacerlo bien y con perspectivas de éxito social o económico. El concepto se convirtió en un descriptor de la capacidad humana para concretar resultados con eficacia, efectividad y eficiencia, lo que llevó a incorporar el término en la economía desde finales del siglo XVII en el tratado "Ensayo en la naturaleza general del comercio", del banquero parisino Richard Cantillón (Gama 2004).

Desde el siglo XIX y fundamentalmente a partir del siglo XX, el tópico experimenta un proceso de resemantización, cuyo asidero lógico resultó un conjunto de trabajos presentados por autores descollantes en el ámbito de las ciencias económicas, que con mayor o menor alcance aportaron acepciones orientadoras del sentido actual del término. Entre las definiciones más difundidas pueden referirse las siguientes:

Joseph Schumpeter (1942, citado por Andrade y Bravo 2009, 38) conceptualiza el emprendimiento (entrepreneurship) como "el hacer las cosas que generalmente no son realizadas en el curso ordinario de las empresas, es esencialmente un aspecto que está orientado por aspectos de liderazgo".

Para Timmons $(1999,62)$, el emprendimiento "es la capacidad para crear algo partiendo desde cero, complementada con la habilidad para conformar equipos y liderarlos resaltando sus destrezas; la capacidad para gestionar recursos y administrarlos y la pericia para asumir riesgos calculados". 
Burrows y Curran (1989) definen el emprendimiento como un "proceso innovador que excluye las imitaciones de empresas o las adquisiciones hechas por los gerentes". Gartner (citado por Julien 2005, 26), por su parte, enfatiza en la idea de que "el emprendimiento surge del comportamiento, conduciendo este a la creación de una nueva organización”.

La Organización para la Cooperación y el Desarrollo Económico (OCDE citado por Andrade y Bravo 2009, 39) amplía las definiciones afirmando que "el emprendimiento es una manera de ver las cosas y un proceso para crear y desarrollar actividades económicas con base en el riesgo, la creatividad y la innovación, al gestionar una organización nueva o una ya existente".

A partir de las definiciones anteriores, Julien (2005) aporta un criterio clasificatorio del emprendimiento en relación con las evidencias de pertinencia e impacto de la actividad en cuestión. En este sentido, establece la siguiente clasificación:

- Aquel que crea una nueva empresa, con diferencias evidentes a otras de su ramo.

- El que adquiere una empresa y le da un sentido diferente del que tradicionalmente orientaba su dinámica.

- El que se enfoca en el mercado existente y es capaz de sintetizar en sus productos y servicios las demandas, necesidades y requerimientos socioproductivos.

- El que apunta a un nuevo mercado y demuestra capacidad para anticiparse a nuevas tendencias y prever posibles nichos económicos o socioculturales relacionados con su actividad.

- El que es capaz de crear nuevas tendencias, forjar intenciones y determinar niveles de aceptación; además de establecer un sello de calidad de sus producciones y servicios, y entronizar una marca exitosa de identidad.

Desde la percepción de los autores citados, se colige que, la condición fundamental de emprendimiento estriba en el diseño, creación y desarrollo sostenible de nuevas empresas.

En el ámbito latinoamericano son varios los autores que orientan sus esfuerzos en aras de la sistematización y desarrollo del tópico objeto de análisis (Varela 2005; Formichella 2004; Andrade y Bravo 2009). 
Varela define las peculiaridades que caracterizan lo que él denomina: "espíritu empresarial"; lo define como un conjunto de cualidades, tales como: "la capacidad para identificar nuevas oportunidades de negocio [...] la habilidad para encontrar soluciones o respuestas a las oportunidades y necesidades mediante procesos de creatividad e innovación [...], los deseos de implementar dichas respuestas [...], la capacidad de mantener un ritmo constante de trabajo corrigiendo errores y sacando fruto de los aciertos" (Varela 2005, 54).

A partir de los aspectos tratados, es atinado alentar una visión más amplia e integradora del fenómeno, que asuma las perspectivas social, cultural, económica y productiva en el desarrollo de los procesos de generación y redimensionamiento empresarial, entendiendo a la empresa como una forma de organización humana orientada al desarrollo de una actividad o de un conjunto de actividades sistémicamente estructuradas, en función de objetivos previamente pautados.

Esta cosmovisión empresarial sitúa a la forma de organización analizada en el óbice de tres formas concretas de interacción: las relaciones interpersonales, regulatorias de los espacios y actividades desarrolladas entre los individuos, con su efecto respectivo en los procesos de toma de decisiones; las relaciones socioculturales, donde se pautan, norman y desarrollan variantes de interacción entre los sujetos sociales y las superestructuras institucionales y burocráticas jurídicamente establecidas; y las relaciones medioambientales, que orientan, jerarquizan y dan sinergia a los ecosistemas organizacionales, a los efectos de su devenir como espacio de confluencia entre los recursos humanos, materiales, financieros, tecnológicos y contextuales.

A partir de estos elementos, se debe considerar al emprendimiento como un proceso de integración de competencias de índoles y perfiles diversos en aras de la gestación, sustentación, implementación y validación de propuestas orientadas a la instrumentación de nuevas variantes, alternativas y prácticas, capaces de responder a las necesidades humanas, organizacionales, políticas y económicas del desarrollo.

La fortaleza de responder a tan amplia gama de necesidades le da un sentido pragmático a la proyección del emprendimiento, lo que dota al fenómeno de potencialidad, en virtud de la implicación de los resultados devenidos de la actividad creativa de sujetos, instituciones y entornos. 
Sobre esta base, la trascendencia de orientar la educación universitaria en función del desarrollo de emprendimiento estriba en el reconocimiento de la importancia de este tipo especial de actividad y de los sujetos y grupos sociales que la asumen, para el desarrollo integral de la sociedad y las economías nacionales, regionales y locales. Al respecto, se coincide con Varela cuando afirma que: "si un país incrementa significativamente el número de empresas y logra, no solo que muchas de ellas se mantengan y crezcan, sino incuben nuevos proyectos empresariales; entonces el número de oportunidades de empleo y de bienestar crecerá para esa nación" (Varela 2005, 79).

En esta misma línea de análisis los autores Andrade y Bravo precisan que para el logro de un sistema de desarrollo de una cultura empresarial se precisa de dos aspectos primordiales: "La aparición (producción) de nuevos empresarios, a través de procesos formativos, educativos y de capacitación. Este es el papel que debe cumplir el sistema educativo; y el desarrollo de circunstancias favorables, es decir, de una serie de organizaciones públicas y privadas, involucradas y previstas para facilitar la labor de crear empresa" $(2009,40)$.

\section{La innovación en el ámbito del emprendimiento universitario}

Los referentes teórico-metodológicos de la innovación se agrupan en tres modelos teóricos fundamentales: el modelo de investigación y desarrollo, el modelo de interacción social y el modelo de resolución de problemas (Laurencio y Farfán 2014). En el primer grupo, referente al modelo de investigación y desarrollo, se agrupan los trabajos de Brickell (1964), Clark y Guba (1966) y Havelock (1973).

Las perspectivas fundamentales de este enfoque redundan en la asunción de la innovación como proceso orientado a la proyección de investigación en función del desarrollo integral de procesos e instituciones, las que, por su interacción sistémica, se benefician de esta, sea cual fuere el campo de aplicación científico-tecnológica que se produzca en sus áreas y funciones.

El segundo grupo, concerniente al modelo de interacción social, en términos generales analiza las perspectivas teórico-metodológicas de este enfoque que sustentan la concepción de la innovación como un proceso de in- 
teracción social, mediado por la producción e intervención científico-formativa, en función del perfeccionamiento de las actividades, áreas y funciones sustantivas en su integralidad. En tal sentido, este proceso orienta, define y fundamenta la interdependencia y sinergia de actores, procesos e instituciones, en el contexto del proceso de formación integral de los sujetos sociales y de la sociedad en su conjunto.

En el tercer grupo, relativo al modelo de resolución de problemas, confluyen los trabajos de Sancho y otros (1993), Parra y otros (1997), Blanco y Messina (2000) y Libedisnski (2001).

La principal regularidad de este enfoque radica en la asunción de la innovación como espacio de confluencia de los recursos humanos, financieros, materiales y organizacionales; en virtud de la producción, fundamentación, adopción y sistematización de propuestas y buenas prácticas, que hagan posible la superación de las contradicciones, limitaciones y problemáticas que afectan al éxito de las acciones, procesos y funciones organizacionales.

Un procedimiento de análisis que triangule los modelos previos revela con meridiana claridad los núcleos conceptuales básicos de la innovación. En primera instancia, la consideración del carácter sistémico y procesual de la innovación, vista desde las perspectivas de la participación de los actores en su desarrollo, y de la relación de los componentes, actividades y funciones, en el ámbito del perfeccionamiento de los subprocesos integrados al proceso general de desarrollo institucional.

Como puede advertirse, a partir de tales postulados la visión, alcance y proyecciones de la innovación de cara al emprendimiento supera las fronteras de las instituciones y "se torna un mecanismo de interacción entre la universidad y la sociedad, de inminente rigor si se asume el carácter regulador y proactivo del desarrollo educativo del emprendimiento, en aras del bien común y de un desarrollo social sostenible" (Laurencio y Farfán 2014, 35).

Es evidente que el fenómeno en estudio obedece claramente a un esquema sociológico de relación, donde se presentan tres dimensiones básicas:

1. Socioeconómica: Relacionada con las políticas estatales y gubernamentales en general, y las políticas económicas y empresariales en particular; los proyectos de educación no formal, informal y no escolarizados; el papel y proyección de los medios masivos de comunicación; y la integra- 
ción de la totalidad y pluralidad de los sistemas de influencia en torno al bien común como paradigma de desarrollo sostenible.

2. Institucional-empresarial: Concerniente al estrechamiento del lazo entre la universidad, la sociedad y el universo institucional, organizacional y empresarial del contexto. Esta dimensión tiene relación directa con el clima organizacional, la logística e infraestructura de entidades, organizaciones y empresas; así como con las condiciones de trabajo y los mecanismos de estimulación existente.

3. Curricular-pedagógica: Referente a la implicación formal de la innovación orientada al emprendimiento en el proyecto educativo, transversalmente integrado al perfil de formación profesional y a los planes y programas de estudio, siempre en consecuencia con las demandas de la época, la sociedad, la profesión y el contexto. En esta dimensión la innovación trasciende a todos los escenarios de formación, de modo que no solo se crea una cultura de emprendimiento, sino que se contribuya a la formación de sujetos innovadores, portadores y garantes de esa cultura.

Desde tales perspectivas, el quehacer de la docencia universitaria necesariamente debe orientar sus esfuerzos para fomentar el emprendimiento como un tema transversal, imprescindible para la formación integral de los sujetos sociales. De este modo se es consecuente con la responsabilidad social universitaria tanto en su función específica como a su relación con las otras funciones sustantivas -léase investigación, docencia y vinculación con la sociedad- que abocarán su proyección formativa en proporcionalidad con los criterios establecidos.

Entre los requerimientos necesarios para sustentar y favorecer la práctica innovadora orientada al emprendimiento en las instituciones de educación superior, vistos desde las perspectivas de interacción de dos niveles de relación: el organizacional y el intelectual, pueden plantearse los siguientes:

\section{Requerimientos organizacionales}

- Existencia de una política asertiva y funcional, que trace las líneas fundamentales de innovación, las prioridades y vías de concreción necesarias, el apoyo logístico y respaldo institucional y las normas que rigen la práctica emprendedora. 
- Disponibilidad de mecanismos operativos y eficientes de control y seguimiento de los proceso de emprendimiento institucional, de los proyectos a él integrados y de los resultados reales, potenciales y requeridos.

- Cobertura de ámbitos, escenarios, espacios y medios para la socialización crítica, divulgación e implementación de los productos resultantes de la actividad de emprendimiento.

- Acceso a recursos materiales, financieros y tecnológicos que permitan la concreción de las acciones concernientes al emprendimiento en las áreas y actores de la institución.

- Empleo de formas efectivas de estimulación -moral y material- de individuos o colectivos con buenos resultados en la actividad de emprendimiento, en correspondencia con el perfil y las posibilidades de la institución.

- Creación de mecanismos formales -institucionales e interinstitucionales- para la validación, implementación y generalización de prácticas y experiencias de emprendimiento.

\section{Requerimientos intelectuales}

- Desarrollo de competencias, referidas a la creación y proyección de redes de trabajo, al uso creativo de las tecnologías de la información y la comunicación, con énfasis en aquellas que propician el trabajo colaborativo y la socialización en red; al dominio de la metodología de la investigación y de la mercadotecnia, de los procedimientos de indagación y de los recursos tecnológicos en que se apoyan; a la valoración crítica de las implicaciones socioeconómicas, culturales e ideopolíticas de los resultados, productos y servicios científico-tecnológicos; al compromiso real y la responsabilidad manifiesta con respecto al impacto y pertinencia de la práctica emprendedora.

- Acceso a la información disponible en torno a las disímiles líneas en que se proyectan los emprendimientos.

- Promoción de la cooperación y la colaboración tanto en los ámbitos de localización, procesamiento y manejo de la información y del conocimiento, como en los ámbitos de la creación, implementación y generalización de los resultados emprendedores. 
- Desarrollo de un perfil ético que someta al escrutinio axiológico, a la totalidad de los procesos de creación, instrumentación, socialización y generalización de los resultados de emprendimientos generados.

- Compromiso ideopolítico y sociocultural con los valores que sustentan el devenir, la actualidad y el futuro de la identidad y el proyecto social establecido en común acuerdo por la sociedad. Ello supone el respeto a la diversidad, un manejo intercultural de lo social y una asunción responsable de la normatividad jurídica y social, alejada de posibles prácticas corruptas, delictivas e ilegales.

- Proyección evidente y demostrable de la práctica emprendedora, en virtud del desarrollo integral sostenible y del bien común como paradigma de desarrollo.

\section{La creatividad como factor formativo del emprendimiento universitario}

La creatividad es un rasgo esencial en la naturaleza humana, es decir, constituye la capacidad de generar problemas y solucionarlos, bajo condiciones variables. Esta capacidad, dada sus características dinamizadoras en la actividad, genera la movilidad y la transformación de la misma.

La creatividad integra de una manera coherente y armónica la creatividad que se manifiesta en el aula, con la creatividad que se manifiesta en el ejercicio concreto de la actividad social, cultural y profesional. La amplitud y variedad del concepto creatividad profesional implica la triangulación lógica y práctica entre la creatividad y la profesión, cuestión que por el nivel de abstracción que exige, resulta en extremo difícil describir; no obstante, es ineludible si se pretende alcanzar saldos favorables en lo concerniente a la orientación formativa del tópico.

La creatividad se educa, por lo tanto, hay que propiciar el espacio para cultivarla. Ahora bien, la educación de la creatividad profesional en función del emprendimiento es una tarea compleja y multifactorial. Debe estar dirigida a determinar y descubrir contradicciones propias del ejercicio de la profesión en condiciones cambiantes, de ahí que el proceso de trabajo de la creatividad en este ámbito esté determinado por problemas profesionales, y 
comienza cuando el docente pone al estudiante ante las contradicciones, de forma tal que se produzca la toma de conciencia del problema y surja en él la necesidad de resolverlo.

La creatividad orientada al emprendimiento, por lo tanto, implica el cumplimiento de las exigencias de la labor docente en diversas condiciones. Para ello es recomendable tener en cuenta los elementos que a continuación se sintetizan:

Indicadores de la creatividad profesional que propenden al emprendimiento.

1. Originalidad: Es la capacidad del individuo para generar ideas y/o productos cuya característica es única, de gran interés y aportación social, cultural, económica, productiva o formativa.

Los parámetros son: novedad (apartarse de lo habitual); manifestación inédita (descubrir algo no conocido); singularidad (lo único apropiado y genuino), e imaginación (creación mental de nuevas realidades).

Sus formas de estimulación son: la reflexión de actitudes, comportamientos y hábitos de conducta cotidiana, en las diferentes actividades y funciones, buscando formas nuevas de respuesta y solución, y la realización de actividades de innovación, ingenio e inventiva, cambiando patrones, marcos de referencia y paradigmas.

2. Fluidez: Es la capacidad para producir ideas en cantidad y calidad de una manera permanente y expedita. Es el proceso de generación de descubrimientos que no se interrumpen; implica además, la productividad del pensamiento técnico en la búsqueda de contradicciones y en la solución de problemas.

Los parámetros son: variedad y agilidad de pensamiento funcional y relaciones sinápticas; repentismo (rapidez para responder situaciones imprevistas); posjuicio (creación libre de requisitos), y expresión (capacidad de percibir el mundo y expresarlo).

Sus formas de estimulación son: ejercicio constante del pensamiento técnico en función de solución de retos profesionales, en la búsqueda de mayor cantidad de ideas, tanto insólitas como convencionales, que solucionen problemas profesionales, y permanente ocupación mental en la búsqueda de diferentes alternativas, en el uso de diferentes métodos y en la asociación nutrida y permanente de ideas. 
3. Divergencia: Es la capacidad del individuo para analizar lo opuesto, para visualizar lo diferente, para contrariar el juicio y para encontrar caminos diferentes. La divergencia es el tránsito por las ideas de la problematización.

Los parámetros son: espíritu crítico (búsqueda y contraposición de argumento); reflexión (reconsideración del pensamiento); metodologías alternativas (posibilidad hacia nuevos paradigmas), y pensamiento lateral (alternativa de llegada y de encuentro).

Sus formas de estimulación son: ejercicios de simulación, nuevos usos y creación de objetos insólitos; diseño de elementos en condiciones no acostumbradas, y desarrollo de situaciones no convencionales.

4. Flexibilidad: Es la capacidad del individuo para organizar los hechos dentro de diversas y amplias categorías. Es la capacidad de modificación, de variación en comportamientos, actitudes, objetos, objetivos y métodos.

Los parámetros son: reflexión (volver a examinar); argumentación (apertura, confrontación de ideas, diversidad y pluralismo); versatilidad (amplitud de criterio y facilidad de adaptación), y proyección (capacidad de delinear y afrontar el futuro).

Sus formas de estimulación son: enumeración de la variedad de consecuencias sobre una acción específica; búsqueda de diversidad de asociaciones sobre un hecho u objeto; riqueza de argumentación sobre un hecho o alternativa de solución, y búsqueda de argumentos para los diversos factores de un hecho.

5. Sensibilidad: Es la capacidad del individuo para percibir y expresar el mundo en sus múltiples dimensiones, para identificarse con una situación o problema planteado. Es la concentración y compenetración con la acción, la capacidad de respuesta a partir de las demandas del entorno, el proceso y sus principales actores.

Los parámetros son: percepción (impresión del sentido); expresión (formas de manifestar las ideas); permeabilidad (impacto de la impresión); concentración (pensamiento profundo y enfocado a la penetración), e identificación y empatía, función social, compromiso y participación.

Sus formas de estimulación son: cultivar el amor, el afecto y la ternura; incentivar los sentidos mediante ejercicios sonoros, de observación 
y acción táctil, y uso simultáneo de diferentes sentidos en función de un mismo objetivo.

6. Motivación: Es aquella capacidad que, desde la óptica de la relación que existe entre lo cognitivo y lo afectivo, genera una disposición positiva ante el requerimiento de solución de problemas profesionales.

Los parámetros son: modo de actuación profesional; comportamiento sociocultural, laboral, intelectual y humano en general; establecimiento de contradicciones entre lo conocido y lo desconocido, y comportamiento cotidiano.

Sus formas de estimulación son: empleo de situaciones de aprendizaje, juegos didácticos, entretenimientos del saber y situaciones problemáticas; solución de problemas profesionales que revelen una contradicción técnica, e implicar al estudiante en el proceso de aprendizaje profesional, como sujeto activo del mismo.

7. Independencia: Es la capacidad para comprender, formular y realizar las tareas profesionales, cognoscitivas y metodológicas, según su propia iniciativa, sin ayuda alguna y de forma individual; resultante de la interacción productiva previa con otros sujetos, entornos y procesos.

Los parámetros son: búsqueda, selección y procesamiento de la información técnica necesaria para resolver las tareas profesionales; valoración crítica de los resultados obtenidos, y libertad para elegir vías para la realización de proyectos y tareas.

Sus formas de estimulación son: mediante la creación de situaciones problemáticas profesionales que estimulen la actividad cognoscitiva. Enseñar a razonar y a estudiar; variar la correlación entre las actividades del profesor o tutor y las de los alumnos, a favor de estos últimos, e incrementar paulatinamente el grado de complejidad de las tareas profesionales y de los materiales técnicos de estudio.

Estos indicadores, reconocidos por varios investigadores como dimensiones, permiten determinar y elevar el nivel de desarrollo creativo en función del emprendimiento humano, que resultaría imposible de concebir y concretar sin la existencia de entornos favorecedores de la creatividad; y sin la proyección creativa de los emprendedores en virtud de la asunción de nuevos retos y perspectivas de trabajo. 
Es preciso, además, cumplimentar determinadas exigencias que son indispensables para favorecer el desarrollo de la creatividad.

1. Desarrollar la creatividad en los directivos, profesores y tutores:

- Este es el primer requisito, la primera condición, para que sirva de modelo al alumno. Se necesita un docente que dirija científicamente el aprendizaje de los estudiantes con un enfoque de sistema del proceso pedagógico profesional en función de la creatividad y el emprendimiento.

- Se ha constatado que los docentes y tutores altamente creativos generan el desarrollo de una alta creatividad profesional en los estudiantes y, por ende, se tornan emprendedores potenciales, por lo que es necesario capacitar a los docentes con bajo nivel de creatividad para que logren desarrollar esta cualidad en sus estudiantes. "Lo cierto es que un maestro que no es creador ni emprendedor, no puede enseñar a sus alumnos a ser creadores y menos aún emprendedores" (Martínez 1990, 49).

2. Diseñar una estrategia coherente e integradora de trabajo metodológico:

- En la estrategia de trabajo metodológico deben estar implicadas todas las asignaturas del currículo y las acciones de los docentes.

- El desarrollo de la creatividad no ocurre en un momento del proceso pedagógico profesional, existe durante todo el proceso y en cada uno de sus componentes.

- El emprendimiento no es un momento, es una dimensión estable que abarca un largo período de tiempo. Hace falta genio pero realizado en el amor, en la vida y en el trabajo.

- La creatividad no puede ser desarrollada solo mediante los esfuerzos de un profesor o tutor, sino que se requieren acciones coordinadas de todo el colectivo pedagógico del departamento y de los sistemas de influencia educativa relacionados. Agréguese a ello que el emprendimiento es un trabajo de equipo.

3. Estructurar sistémicamente los componentes académico, laboral e investigativo, en función de la activación del emprendimiento profesional creativo:

- El perfeccionamiento de los métodos de enseñanza contribuye a activar el aprendizaje profesional de los estudiantes, pero esto no resulta 
suficiente para desarrollar la creatividad profesional, sino que es necesario emplear los métodos de enseñanza en forma de sistema, con una concepción didáctica desarrolladora.

- Los métodos activos de enseñanza profesional deben emplearse tanto en la entidad escolar como en el ámbito social, tanto en actividades docentes como extradocentes, extraescolares, productivas y de investigación, solo así contribuirán al desarrollo del emprendimiento en los estudiantes. El profesor o tutor deben propiciar la originalidad en el proceso de aprendizaje.

- La clase debe propiciar la fantasía y la imaginación creadora a partir de la combinación de imágenes e ideas, las analogías y las asociaciones.

- Para desarrollar la creatividad y el emprendimiento es importante utilizar imágenes y metáforas, tratar de fundir los dos conceptos técnicos en una nueva realidad productiva para explicar lo desconocido a partir de algo conocido.

- Debe promocionarse la elaboración de algo nuevo y su aplicación práctica. Debe estimularse la elaboración de preguntas y de respuestas con relación al contenido que se trabaja, propiciando la elaboración de hipótesis y la comprobación de las mismas por vías no tradicionales.

- La clase debe propiciar la búsqueda, detección y planteamiento de problemas profesionales, y deben estimularse diversas alternativas de solución de los mismos.

- Debe instarse a los alumnos a completar ideas y esbozos, y a expresarlas verbalmente, junto a la complejización creciente de las tareas a desarrollar.

4. Implicar al estudiante en su propio proceso de aprendizaje:

- Los estudiantes deben recibir progresivamente la responsabilidad sobre su propio aprendizaje; necesitan darse cuenta que solo pueden aprender si lo hacen por sí mismos y que desarrollarán habilidades profesionales en la medida en que se impliquen a sí mismos, activa y voluntariamente, en el proceso pedagógico.

- Es evidente que la educación creativa requiere en primera instancia de un compromiso con la creación, que asumirá la creatividad como un mecanismo de concreción de sus propósitos: "otro de los cometidos de 
la educación creativa sería, pues, el de explicar a los escolares que es necesaria una determinada actitud para el aprendizaje creativo y para el emprendimiento: el alumno debe saber que de él se esperan creatividad y emprendimiento" (Landau 1987, 53).

5. Formar hábitos de trabajo y aplicar técnicas que lleven al descubrimiento, a la investigación y al estudio:

- Las técnicas de investigación son las que preparan para la autoeducación. Esto implica que el profesor debe ser capaz de adentrarse junto a sus alumnos por caminos desconocidos también para él.

- El docente no debe ser autoritario ni asumir una posición de poder; por el contrario, debe manifestar amplitud de criterios, ser flexible, aceptar las ideas de los alumnos, aun cuando estos piensen diferente a él.

- No imponer un criterio y estimular la libre expresión de ideas, luchar por eliminar o atenuar los obstáculos y resistencias que surjan en el grupo o en algún estudiante.

- Es menester ser emprendedor, tratar de no perder nunca el buen humor, actuar con jocosidad y dominar las técnicas y dinámicas grupales.

6. Crear un ambiente que estimule el desacuerdo y provoque la duda en el alumno:

- Es necesario utilizar los desacuerdos de manera constructiva, desarrollando el contenido profesional con un enfoque del problema.

- El docente debe provocar la duda en el estudiante, así como el cuestionamiento y la insatisfacción con los resultados

- Hay que favorecer un comportamiento activo y transformador de la realidad, impulsar el cuestionamiento, la movilidad y el cambio de lo existente, de lo tradicional y convencional.

- El docente debe potenciar el enfrentamiento a los obstáculos que impiden la concreción de las ideas nuevas y la búsqueda de las vías para superar los lastres consecuentemente.

7. Desarrollar habilidades para plantear y resolver situaciones problemáticas:

- Resaltar las expresiones de creatividad en el proceso de apropiación del conocimiento que son: el planteamiento de problemas y la problematización de los contenidos que se estudian. 
- La solución de problemas es para muchos autores la vía principal por la que se manifiesta la creatividad.

- La solución de problemas como metodología de enseñanza puede aplicarse en todas las áreas del saber.

- La solución de situaciones problemáticas profesionales debe implicar la valoración de opciones, ofreciendo las verdades profesionales no como conocimientos acabados, sino como aproximaciones graduales y progresivas a la realidad objeto de estudio y transformación.

- Es necesario despertar la curiosidad en el estudiante y conducirlo a niveles diferentes, mostrarle las contradicciones de la especialidad que estudia y, sobre esa base, incitarlo a la búsqueda de alternativas para la superación de dichas contradicciones.

Se considera que no solo quien solucione un problema, sino quien sea capaz de descubrirlo y plantearlo, es una persona creativa. De ahí que, donde haya un problema, está escondida la posibilidad real y tangible del desarrollo de la creatividad: "Es más importante descubrir problemas que resolverlos, una psiquis que problematiza su realidad se anticipa a las futuras experiencias, y por tanto puede dar mejores respuestas a los problemas de la vida cotidiana que se le presentan" (Betancourt 1994, 83).

Desde esta perspectiva, encontrar un problema, es decir, descubrirlo, formularlo, plantearlo, "representa un acto creativo perfectamente distinguible, y de igual o mayor valor que el hallar una solución” (González 1990, 25). El descubrimiento es una manifestación diáfana de la creatividad y el emprendimiento. Cuando se trabaja con espíritu de creatividad hay una interrogante, un problema a solucionar; pero no hay una respuesta única, hay varias, las que se dan en el momento y las que están por aparecer.

8. Tratar con respeto las ideas y preguntas insólitas:

- El docente debe reconocer el valor de las ideas de los alumnos, y plantear proposiciones que contrasten con los conocimientos previos que el estudiante posee.

- Hay que propiciar un clima creativo en la clase, lo cual implica propiciar la generación de ideas y su libre expresión, así como estimular las ideas nuevas y originales, los modos no comunes y convencionales de analizar las cosas. 
- La imaginación desempeña un importante papel en la creatividad y el emprendimiento.

- Es importante respetar las ideas e iniciativas personales, evitar la evaluación crítica inmediata de las ideas expresadas y aplazar para un momento posterior dicha valoración.

- Es necesario estimular la participación del alumno en los debates, propiciando que aparezcan vivencias afectivas positivas en el proceso, es decir, el disfrute y satisfacción personal en el proceso de creación y emprendimiento.

- Hay que felicitar por los éxitos y no insistir demasiado en el fracaso, con el fin de eliminar las inhibiciones, las barreras, las resistencias y los esquemas.

- Hay que enseñar a los alumnos a aprender de los errores. Los adultos aprenden, adquieren experiencias en buena medida de los errores cometidos, se equivocan y toleran sus equivocaciones; sin embargo, a los alumnos se los sanciona por el error, el sistema otorga una mejor calificación al que se equivoque menos, y peor calificación al que se equivoque más.

Como se puede apreciar el desarrollo de la creatividad como factor de emprendimiento no es un camino fácil; de igual modo que el reto que su proyección presupone, es ineludible la asunción decidida de su orientación formativa para garantizar niveles cualitativamente superiores de eficiencia académica, laboral e investigativa en la formación integral de los educandos; y en el perfeccionamiento constante de la labor docente en este ámbito, visto desde el prisma del desarrollo formativo del emprendimiento.

\section{El desarrollo de competencias para el emprendimiento en el contexto universitario}

Un aspecto de inminente rigor en el desarrollo educativo del emprendimiento universitario es el referido al enfoque de formación que más se acerca a la lógica procedimental del fenómeno en cuestión y sus factores asociados. En este sentido se coincide con Andrade y Bravo (2009) en que 
"la formación de competencias laborales y el desarrollo de actitudes de emprendimiento en la educación superior, puede ser concebida como una oportunidad de formación profesional que este nivel de educación deberá ofrecer a sus estudiantes, dando la oportunidad de abrir nuevos espacios y generar las condiciones académicas necesarias para que su desarrollo se lleve a cabo de forma integral" (Andrade y Bravo 2009, 45).

Esto es vital si se tienen en cuenta las tendencias que en la actualidad marcan el sentido de la educación para el emprendimiento. En Europa el tema constituye un ámbito esencial de reflexión científica y una preocupación permanente de académicos, intelectuales, empresarios y directivos vinculados a la universidad. Téngase en cuenta que la Comisión Europea señaló que "la educación y la formación superior deben contribuir a impulsar el desarrollo del espíritu emprendedor, fomentando una actitud favorable, y una mayor sensibilización hacia la profesión de empresario, lo cual redundaría en un mayor número de empresas y en un mayor desarrollo global, regional y nacional" (Comisión Europea 2003, 46).

Como puede apreciarse, el sentido de dicha preocupación se soporta en la realidad de que la formación del emprendimiento resulta equiparable a una formación para la vida, "no solamente para resolver un problema de empleo; implica la adquisición de competencias relacionadas con la creatividad, la flexibilidad, la capacidad de adaptación y la habilidad para aprender a aprender y resolver problemas, capacidades características del comportamiento emprendedor" (Andrade y Bravo 2009, 46).

En igual sentido resulta imprescindible el reconocimiento y la promoción del rol de la universidad como ente desarrollador de la motivación de los estudiantes, por medio de estímulos relacionados con los rasgos, procedimientos y variantes de instrumentación de la actividad empresarial (motivación de logro, independencia, etc.), así como el apoyo docente y logístico que requieren ofrecer universidades, contextos y sociedades, en virtud de fomentar, canalizar y formar inquietudes emprendedoras en los sujetos en formación, ya sea en el pregrado como en los ámbitos del posgrado y la formación continua.

Al respecto, Toledano sugiere que a la par de disponer del apoyo institucional y contextual requerido para la formación de emprendedores en el nivel universitario, es menester conocer la predisposición de los estudiantes para 
afrontar el desarrollo del emprendimiento. Desde tal óptica el autor citado asevera que "una iniciativa educativa para desarrollar competencias para el emprendimiento deberá contemplar dicho punto de partida preguntándose: ¿existe una intención por parte de los estudiantes a ser emprendedores? Complementada con la pregunta ¿existe relación entre el deseo de ser emprendedor y el desarrollo de la didáctica en la práctica docente?" (Toledano 2006, 49).

El análisis de estas interrogantes, apoyado en procedimientos de tabulación de respuestas, evidenció en su estudio implementado en la Universidad de Huelva (España) -estudio realizado por Toledano 2006- la existencia de una mayor propensión hacia la creación de empresas por parte de los alumnos de sexo masculino, dotados de conocimientos en torno a la creación de empresas y con familiares o amistades imbricadas en el ámbito empresarial. A ello súmese como factor de predisposición resultante de dicho estudio, el hecho de que los estudiantes cuenten con experiencia laboral.

Otras indagaciones, como el caso del estudio comparado del proceso emprendedor en países de América Latina, sur de Europa y este de Asia (Koenig y Kantis 2003), demuestran la relación entre el nivel de desarrollo alcanzado por los países con respecto al perfil emprendedor de sus ciudadanos y a la proyección educativa del emprendimiento en sus instituciones educativas en general, con énfasis en la educación superior en particular.

Por esta razón, en los países en desarrollo

una de las herramientas para lograr una mayor y mejor formación de competencias para el emprendimiento empresarial de sus ciudadanos es el poder aprovechar conjuntamente la educación y los recursos tecnológicos como mecanismos generadores de creatividad, liderazgo, planeación, organización, innovación y trabajo en equipo; estas características propiciarían el surgimiento de personas más emprendedoras y con ellas el fortalecimiento de la estructura empresarial de las regiones (Andrade y Bravo 2009, 52).

Todo ello ilustra con meridiana claridad la necesidad de realizar acciones para la proyección formativa de la educación en función de la preparación de ciudadanos e instituciones capaces de afrontar, con altas probabilidades de éxito, las exigencias de las realidades en su multidimensionalidad, donde el mercado y el desarrollo económico tienen una incidencia notable e ineludible. 
Queda claro entonces el rol que debe desempeñar en este contexto el sector educativo en sus diferentes niveles y las universidades como estrato superior de dicho sistema, a los efectos de garantizar procesos de formación que desarrollen conocimientos, actitudes, valores, capacidades y procedimientos garantes de la inserción de los sujetos sociales en el mundo laboral y en iniciativas de emprendimiento empresarial. "Aunque esta responsabilidad ha sido delegada a los niveles de educación básica y media, es la universidad, por su compromiso social, la llamada a ejecutar procesos formadores más efectivos y eficaces con sus estudiantes y que sean pertinentes a las necesidades de desarrollo del país y de sus regiones" (Andrade y Bravo 2009, 55).

En este ámbito de análisis, Varela (2005) explica la necesidad de la educación empresarial en la universidad:

Debido a la precaria labor investigativa realizada desde el ámbito empresarial en Latinoamérica, la universidad como organización del conocimiento debe asumir el rol de establecer vínculos entre la investigación y el tejido empresarial, asumiendo una nueva forma de educación: la educación empresarial. La responsabilidad de incorporar una cultura empresarial transversal en los currículos de las carreras y posgrados debe ser incorporada por cada universidad atendiendo las particularidades del contexto sociocultural local y unos principios básicos generales entre los cuales se mencionan:

a) La formación de empresarios se logra mediante el desarrollo de competencias personales y profesionales centradas en el ser humano.

b) El emprendimiento -o espíritu empresarial- debe ser el producto de un proceso autónomo de la organización educativa. No es "franquiciable".

c) La educación empresarial debe promover el desarrollo del ser humano, a partir del trabajo sobre actitudes y la posibilidad de autorrealización. El estudiante debe ser capaz de definir su rol, acciones y su propia vida.

d) El resultado no necesariamente es la creación de una empresa, pero sí debe ser el adquirir compromisos de innovación y trascendencia.

e) El proceso es secuencial. Se enuncian cuatro etapas con los estudiantes: formativa, es decir, de hacer conciencia, generar motivación y proveer información; desarrolladora de habilidades; arranque o proveer capacidad administrativa; y de crecimiento, en la cual se brinda capacidad gerencial.

f) La creación de ambientes de aprendizaje que promuevan el pensamiento divergente, que den lugar al caos y a la confusión.

g) Utilizar enfoques metodológicos variados que incentiven, entre otros, el trabajo en equipo, por proyectos y una constante retroalimentación (Varela 2005, 39). 
Una de las figuras más descollantes en el ámbito de la gestión empresarial, Peter Drucker, legitima la posibilidad real de enseñar emprendimiento. En este sentido afirma que la personalidad emprendedora no existe. Las habilidades del emprendedor se pueden aprender, ya que más que un rasgo del carácter es una conducta, una actitud. El emprendedor es la persona capaz de intuir una oportunidad de negocio y poner en práctica acciones arduas, creativas, difíciles y arriesgadas, que terminan en la creación de una empresa o negocio. El emprendimiento puede ser considerado más como una conducta que como un rasgo del carácter y, por tanto, puede ser enseñable. (Drucker 1986).

En igual sentido otro importante autor, Cortés, alude:

el proceso que posibilita el poder enseñar emprendimiento tiene mayor relación con la metodología abordada que con el contenido de los cursos desarrollados para su enseñanza, y expone que es la forma en que el profesor aborda el curso, la clave para lograr hacerlo enseñable. Un elemento también indispensable es que para desarrollar su capacidad de emprender, los estudiantes como sujetos activos del proceso de enseñanza y aprendizaje deben involucrarse en este proceso, no solo con disponibilidad para que alguien se lo enseñe sino para aprender de situaciones que él mismo pueda generar en contextos socioculturales y económicos específicos, incrementando las posibilidades de concebir más ampliamente el problema y de desarrollar sus competencias para el emprendimiento articulando teoría y práctica (Cortés 2003, 47).

Los elementos abordados a lo largo del trabajo permiten comprender que la educación de emprendimiento en el contexto universitario no se aboca únicamente a la formación de empresarios, o a la enseñanza de métodos, técnicas y procedimientos orientados a la gestación, fundación y sostenibilidad de empresas económicamente estables y lucrativas. Es mucho más que eso se trata de formar emprendedores para todos los perfiles de actividad sociocultural y profesional, de modo que no solo emprendan los que tienen la ambición justa de ganar y crecer económicamente, sino también los que dedican su vida personal y profesional al servicio de la sociedad. Desde esta perspectiva es prioritario educar un ser emprendedor ligado a los procesos cognitivos y volitivos del emprendimiento;

Es decir, formar a los estudiantes con actitudes proactivas, que los hagan capaces de proponer situaciones factibles de realizar en su contexto, a partir de las cuales el sujeto estará en la capacidad de prever dificultades y obstáculos que puedan dificultar el alcance de sus 
logros, de sus objetivos, y que sean capaces de proponer alternativas reales de solución para ellos (Andrade y Bravo 2009, 57).

Garantizar este tipo de formación académica en la realidad universitaria amerita el despliegue en sus contextos de formación de nuevas formas, metodologías, enfoques y estrategias didácticas que rebasen las fronteras de la enseñanza tradicional, y promuevan el protagonismo y la proactividad estudiantil, de modo que hagan posible el desarrollo de los procesos de enseñanza-aprendizaje, a partir de criterios y concepciones de avanzada redundantes en la asunción del rol activo de los estudiantes en la construcción de sus aprendizajes guiados permanentemente por sus docentes. De esta forma se elude cualquier intento de imposición docente hacia el estudiante, promovido por un tratamiento vertical de la comunicación y el manejo de la información. Una educación para el emprendimiento requiere del desarrollo de un estudiante capaz de emprender incluso el desarrollo de su propio aprendizaje, como sujeto dinamizador de los procesos académicos.

\section{Conclusiones}

La universidad ecuatoriana y en general quienes son docentes universitarios deben inculcar y fomentar en sus estudiantes el interés por emprender, pero un emprendimiento que sea previamente analizado y planificado, un emprendimiento que contemple siempre ese aspecto innovador necesario e indispensable en cada uno de los intentos.

La educación y la formación deben contribuir a impulsar el espíritu emprendedor, fomentando una actitud favorable, la sensibilización hacia las salidas profesionales como empresarios y las competencias.

\section{Referencias}

Andrade, Milton, y Wilmer Bravo. 2009. Análisis económico de eficiencia técnica en cuatro sectores empresariales de Florencia. Documento de investigación. Universidad de la Amazonía, Florencia. Consulta: abril de 2016. 〈http://www.udla.edu.co/revistas/index. php/amazonia-investiga/article/view/14〉. 
Bentancourt, Julián. 1994. Atmósferas creativas 2: rompiendo candados mentales. Ciudad de México: El Manual Moderno.

Blanco, Rosa, y Graciela Messina. 2000. Estado del arte sobre las innovaciones educativas en América Latina. Santiago: Convenio Andrés Bello / UNESCO.

Brickell, Henry. 1964. "State Organization for Educational Change: A Case Study and a Proposal”. En Henry Brickell, edit., Innovation in Education: 493-531. Nueva York: Springer.

Burrows, Roger, y James Curran. 1989. "Sociological Research on Service Sector Small Businesses: Some Conceptual Considerations". Work, Employment and Society 3, No. 4: $527-$ 539.

Clark, David, y Egon Guba. 1966. "Effecting Change in Institutions of Higher Education". Documento de trabajo, UCEA-International Inter-Visitation Program. Consulta: noviembre de 2016. 〈http://files.eric.ed.gov/fulltext/ED028685.pdf〉.

Comisión Europea. 2003. Libro verde: el espíritu empresarial en Europa. Bruselas: Comisión de las Comunidades Europeas.

Cortés, Patricio. 2003. "Enseñar a emprender es cosa de método". Diario Financiero (17 de junio de 2003). Consulta: abril de 2016. 〈http://www.ceo.cl/609/article-32869.html〉.

Drucker, Peter. 1986. La innovación y el empresariado innovador: la práctica y los principios. Buenos Aires: Norma.

Formichella, María. 2004. El concepto de emprendimiento y su relación con la educación, el empleo y el desarrollo local. Buenos Aires: Instituto Nacional de Tecnología Agropecuaria / Gestión del Emprendimiento y la Innovación. Consulta: noviembre de 2016. 〈http://mu nicipios.unq.edu.ar/modules/mislibros/archivos/MonografiaVersionFinal.pdf».

Gama, Soledad. 2004. "Pedagogía activa del emprendimiento para el desarrollo económico local: el caso del colegio Juan Rulfo de USME, Bogotá". Tesis de maestría en Planificación y Administración del Desarrollo Regional. Universidad de los Andes, Bogotá.

González Valdés, América. 1990. "Conceptualización de la creatividad en Prycrea”. Revista Cubana de Psicología 19, No. 3: 3-14.

Havelock, Ronald. 1973. Models of the Innovation Process in US School Districts. Ginebra: UNESCO.

Herrera, Carmen, y Luz Montoya. 2013. "El emprendedor: una aproximación a su definición y caracterización”. Punto de Vista 4, No. 7: 7-30.

Julien, Pierre André. 2005. Emprendimiento regional y economía del conocimiento: una metáfora de las novelas policíacas. Bogotá: Pontificia Universidad Javeriana.

Kantis, Hugo. 2002. Empresarialidad en economías emergentes: creación y desarrollo de nuevas empresas en América Latina y el Este de Asia. Buenos Aires: BID.

Koenig, Virginia, y Hugo Kantis. 2003. "Nacimiento y desarrollo de empresas dinámicas en áreas locales metropolitanas". En Hugo Kantis, edit., Desarrollo emprendedor: América Latina y la experiencia internacional: 35-56. Buenos Aires: Banco Interamericano de Desarrollo.

Landau, Erika. 1987. El vivir creativo: teoría y práctica de la creatividad. Barcelona: Heber. 
Laurencio, Amauris, y Pablo Farfán. 2014. Concepción y praxis de la innovación educativa en la universidad. La Habana: UNESCO.

Libedinsky, Marta. 2001. La innovación en la enseñanza: diseño y documentación de experiencias de aula. Barcelona: Paidós.

Martínez Llantada, Marta. 1990. "La creatividad en la educación postgraduada". Varona, No. 58: 59-66.

Mello, Jeffrey. 2011. Strategic Management of Human Resources. Ohio: South-Western / Cengage Learning.

Parra, Rodrigo, y otros. 1997. Innovación escolar y cambio social. Texas: FES.

Pedraza, Aura, Cristian Ortiz y Sergio Pérez. 2015. "Perfil emprendedor del estudiante de la Universidad Industrial de Santander". Educación en Ingeniería 10, No. 19: 141-150.

Sancho, Juana, y otros. 1993. Aprendiendo de las innovaciones: la perspectiva interpretativa de investigación aplicada a tres estudio de caso. Madrid: Ministerio de Educación y Ciencia.

Sela, Juan Pablo, y Hernán Bacarini. 2009. "Las incubadoras de empresas". Documento de trabajo, 10ma. Reunión Anual de la Red PyME-Mercosur. Universidad Nacional de Luján. Consulta: noviembre de 2016. 〈https://es.scribd.com/document/103385141/PolPub ParquesIncubadorasRedPymes2009〉.

Stevenson, Howard, y Juan Carlos Jarillo. 1990. "A Paradigm of Entrepreneurship: Entrepreneurial Management”. Strategic Management Journal 11, No. 15: 17-27.

Timmons, Jeffry. 1999. New Venture Creation: Entrepeneurship for the 21 Century. Boston: McGraw-Hill Higher Education.

Toledano, Nuria. 2006. "Educación y emprendimiento". Revista de Educación, No. 341: 803825.

Varela, Rodrigo. 2005. "Hacia una universidad con espíritu empresarial”. Forum Empresarial 10, No. 1: 70-84.

Schumpeter, Joseph. 1942. Capitalismo, socialismo y democracia. Madrid: Aguilar. 